\title{
DYNAMIC CHARACTERISTICS OF A DIRECT-PRESSURE SENSING WATER HYDRAULIC RELIEF VALVE
}

\author{
Kenji SUZUKI and Eizo URATA \\ Department of Mechanical Engineering, Faculty of Engineering \\ Kanagawa University \\ 3-27-1 Rokkakubashi, Kanagawa-ku, Yokohama, 221-8686 Japan \\ (E-mail: suzuki@kanagawa-u.ac.jp)
}

\begin{abstract}
This paper deals with dynamic characteristics of a direct-pressure sensing water hydraulic relief valve. Four hydrostatic bearings support the main valve to reduce hysteresis of static characteristics of the valve. Hence, Coulomb friction acting on the main valve is not available as damping force. A damping orifice is inserted between the main- and pilot valves to get a damping force for the main valve, while the orifice diameter affects on stability of the main valve. In addition, the motion of the pilot valve has large effects on the response of the relief valve itself. To show these influences, we compute the response to a step input of relief flowrate with the MATLAB/Simulink. The results show that the design parameters affecting the stability are followings: (1) the damping orifice diameter, (2) spring stiffness for the pilot valve, and (3) volume of a chamber between the damping orifice and the pilot valve.
\end{abstract}

\section{KEY WORDS}

Water hydraulic, Relief valve, Direct pressure sensing, Dynamic characteristic

\section{NOMENCLATURE}

$A^{*}: \quad$ various areas (see Eq. (5)) $\left[\mathrm{m}^{2}\right]$

$c_{m}, c_{p}$ : viscous coefficient of main- and pilot valve, respectively $[\mathrm{N} \cdot \mathrm{s} / \mathrm{m}]$

$C_{b}, C_{d}$ : discharge coefficient of a hydrostatic bearing orifice and a valve, respectively [-]

$d_{*}: \quad$ various diameters (see Figs.(2), (3)) [m]

$d_{i}, D_{i}$ : inner and outer diameter of the $i$-th throttle of main valve, respectively $[\mathrm{m}]$

$h$ : clearance of the first throttle when $x=0$ [m]

$k_{m}, k_{p}$ : spring constant for main- and pilot valve, respectively $[\mathrm{N} / \mathrm{m}]$
$K_{i}: \quad i$-th order coefficient (see Eq.(12)) [-]

$K^{*}$ : $\quad$ various proportional constants (see Eqs.(9),(16))

$l_{s}$ : axial length of clearance between pressuredetecting rod and sleeve [m]

$m_{m}, m_{p}$ : mass of main- and pilot valve, respectively (incl. $1 / 3$ of corresponding spring mass) $[\mathrm{kg}]$

$p^{*}: \quad$ pressure at various chambers $[\mathrm{Pa}]$

$P_{*}: \quad$ dimensionless pressure $\left(=p^{*} /\left.p_{s}\right|_{t=0}\right)[-]$

$P_{i}: \quad$ dimensionless $i$-th pressure overshoot [-]

$P_{o}: \quad$ dimensionless pressure increment [-]

$q^{*}: \quad$ flow rate (see Eqs.(10)-(15)) $\left[\mathrm{m}^{3} / \mathrm{s}\right]$

$r_{d}: \quad$ damping ratio $\left(=P_{2} / R\right)[-]$

$T_{1}$ : time to first overshoot [s] 
$T_{d}:$ time from first overshoot to second one [s]

$T_{s}: \quad$ settling time $[\mathrm{s}]$

$V_{*}: \quad$ volume of various chambers $\left[\mathrm{m}^{3}\right]$

$x$ : displacement of main valve $[\mathrm{m}]$

$X:$ dimensionless displacement of main valve [-]

$x_{0}$ : initial displacement of spring for main valve [m]

$y:$ displacement of poppet valve [m]

$Y:$ dimensionless displacement of poppet valve [-]

$y_{0}:$ initial displacement of spring for poppet valve [m]

$\alpha *$ : equivalent area (see Eq. (8)) $\left[\mathrm{m}^{2}\right]$

$\beta$ : bulk modulus of fluid $[\mathrm{Pa}]$

$\delta_{s}$ : clearance between pressure-detecting rod and sleeve $[\mathrm{m}]$

$\mu: \quad$ viscosity of fluid [Pa.s]

$\theta_{p}:$ half cone angle of poppet valve [-]

$\rho:$ density of fluid $\left[\mathrm{kg} / \mathrm{m}^{3}\right]$

\section{INTRODUCTION}

Since viscosity of water is much lower than that of oil, internal leakage is liable to occur in water hydraulic valves than in oil hydraulic valves. Placing of a packing on sliding part prevents the internal leakage, whereas its Coulomb friction may causes stick-slip, hysteresis, and instability of the motion. To prevent these phenomena, flow through the clearance between a valve and a sleeve is utilised as pilot flow in a water hydraulic high-speed solenoid valve [1]. When the valve is eccentric to the sleeve, however, the flow through the clearance will increase and a hydraulic rock will be liable to occur. In the water hydraulic relief valve dealt with this study, the main valve is supported by hydrostatic supports. Flow through the hydrostatic supports is utilised as pilot flow, by which internal leakage is reduced. A direct pressure-sensing technique [2] is adopted in the pilot valve to decrease pressure override. To suppress cavitation, pressure in relief flow is reduced by two serial restrictors in the main valve $[3,4]$.

Dynamic characteristics of a relief valve are studied by many authors. Some of the studies on a oil hydraulic relief valve are the followings: Shin [5] discussed static and dynamic characteristics of balanced-piston-type relief valve with various design parameters, whereas he has ignored the compressibility of oil; Yao [6] computed dynamic response of direct-pressure sensing relief valve only with one set of design parameters. For a balancedpiston-type water hydraulic relief valve, Hayashi et al. [7, 8] discussed the dynamic characteristics of the valve with some design parameters, including the connected pipeline. For the direct pressure sensing water hydraulic relief valve treated in this study, however, the analysis of dynamic characteristics has not been made.

In this study, effects of various parameters were investigated on the stability and dynamic response for the direct pressure sensing water hydraulic relief valve. The design parameters that affects stability of the valve are shown.

\section{STRUCTURE OF THE VALVE}

Figure 1 shows the structure of the direct-pressure sensing water hydraulic relief valve treated in this study. The features are as follows:

1) The main valve is supported by a hydrostatic support to reduce Coulomb friction. The orifices for the hydrostatic bearings and clearance around the main valve are used as the restrictor from the supply pressure to the pilot pressure. Thus, the flow through the hydrostatic supports is utilised as the pilot flow.

2) To suppress cavitation, the main valve includes two annular throttles with nearly equal diameters. Both of the throttles employ a plane contact because a line contact is liable to change the static characteristics due to wear of the valve and the valve seat.

3) To reduce internal leakage from the pilot valve, a conventional poppet valve with a pressure-detecting rod is adopted. The displacement of the poppet valve is almost determined by the balance of forces due to the supply pressure and the pilot spring.

4) To stabilize the motion of the main valve, a damping orifice is placed between the main- and pilot valves.

5) The main valve is made up from three pieces to improve machining accuracy.

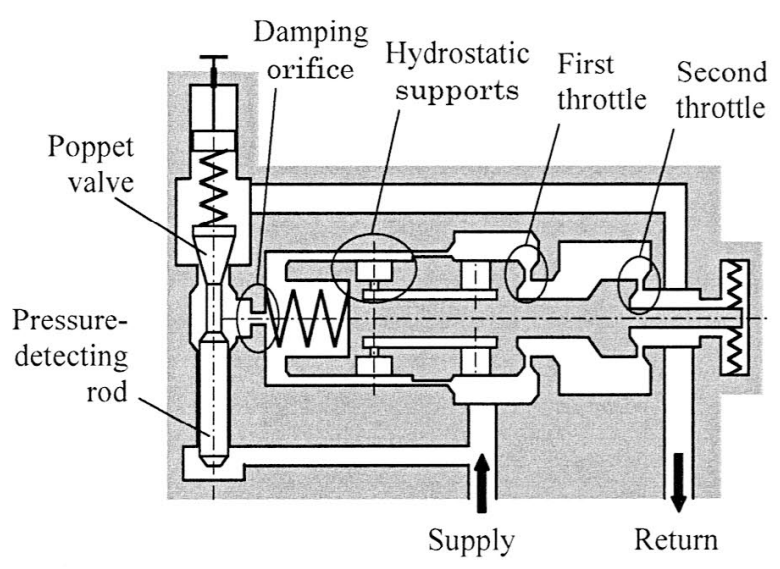

Figure 1 Schema of direct pressure sensing water hydraulic relief valve

\section{SIMULATION MODEL}

Figures 2 and 3 show the model drawing of the main valve and the pilot valve, respectively. 


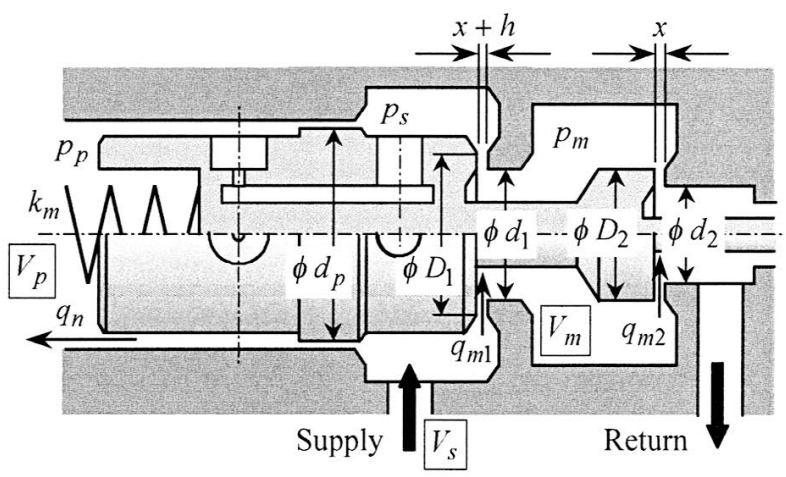

Figure 2 Model drawing of the main valve

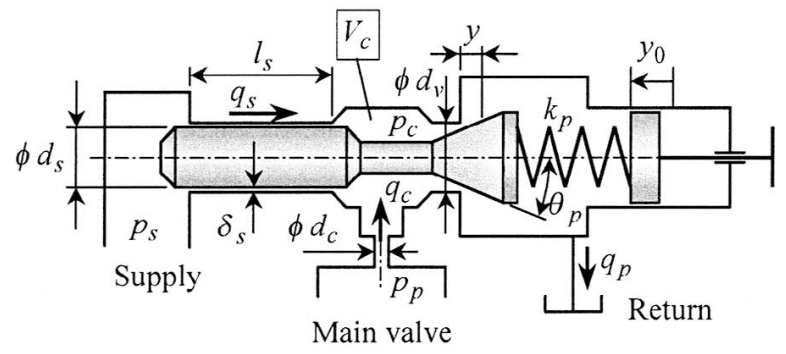

Figure 3 Model drawing of the pilot valve

For the analysis, following assumptions were made:

a) Physical properties of the fluid are constant.

b) Discharge coefficient is constant.

c) Change of the chamber volume by displacement of the valve can be neglected.

d) The valve undergoes no volumetric change under the pressure.

e) The transient flow force can be neglected in the dynamic characteristics as it is small compared with the steady flow force.

f) Coulomb friction acting on the valve can be neglected.

g) The outlet fluid pressure is same as the tank pressure, that is negligibly small compared with the supply pressure.

\section{Basic Equations}

For each of the chambers, equations of continuity considering compressibility of fluid are established as:

$$
\begin{aligned}
& \dot{p}_{s}=\frac{\beta}{V_{s}}\left(q_{\text {in }}-q_{m 1}-q_{n}-q_{s}-A_{m 1} \dot{x}-A_{s} \dot{y}\right), \\
& \dot{p}_{m}=\frac{\beta}{V_{m}}\left(q_{m 1}-q_{m 2}\right), \\
& \dot{p}_{p}=\frac{\beta}{V_{p}}\left(q_{n}-q_{c}+A_{p} \dot{x}\right),
\end{aligned}
$$

$$
\dot{p}_{c}=\frac{\beta}{V_{c}}\left(q_{c}+q_{s}-q_{p}\right)
$$

where

$$
A_{m 1}=\frac{\pi}{4}\left(d_{p}^{2}-d_{1}^{2}\right), A_{s}=\frac{\pi}{4} d_{s}^{2}, \text { and } A_{p}=\frac{\pi}{4} d_{p}^{2} .
$$

Equations of motion for main- and pilot valves are:

$$
\begin{aligned}
& m_{m} \ddot{x}+c_{m} \dot{x}+k_{m}\left(x+x_{0}\right)=\alpha_{s} p_{s}+\alpha_{m} p_{m}-A_{p} p_{p}, \\
& m_{p} \ddot{y}+c_{p} \dot{y}+k_{p}\left(y+y_{0}\right)=A_{s} p_{s}-K_{f} y p_{c},
\end{aligned}
$$

where

$$
\begin{aligned}
& \alpha_{s}=\frac{\pi}{4}\left\{d_{p}^{2}-\frac{D_{1}^{2}-d_{1}^{2}}{\ln \left(D_{1} / d_{1}\right)}\right\} \\
& \alpha_{m}=\frac{\pi}{8}\left\{\frac{D_{1}^{2}-d_{1}^{2}}{\ln \left(D_{1} / d_{1}\right)}-\frac{D_{2}^{2}-d_{2}^{2}}{\ln \left(D_{2} / d_{2}\right)}\right\}
\end{aligned}
$$

and

$$
K_{f}=\pi C_{d} d_{v} \sin 2 \theta_{p}
$$

Equations of flow rate passing through each restrictors are written as:

$$
\begin{aligned}
& q_{m 1}=\operatorname{sgn}\left(p_{s}-p_{m}\right) \pi C_{d} D_{1}(x+h) \sqrt{2\left|p_{s}-p_{m}\right| / \rho} \\
& q_{m 2}=\pi C_{d} D_{2} x \sqrt{2 p_{m} / \rho} \\
& q_{n}=\operatorname{sgn}\left(p_{s}-p_{p}\right) K_{b} \sqrt{p_{s}} \sum_{i=1}^{3}\left\{K_{i}\left|1-p_{p} / p_{s}\right|^{i}\right\} \\
& q_{c}=\operatorname{sgn}\left(p_{p}-p_{c}\right) K_{c} \sqrt{\left|p_{p}-p_{c}\right|} \\
& q_{s}=\operatorname{sgn}\left(p_{s}-p_{c}\right) K_{s}\left|p_{s}-p_{c}\right| \\
& q_{p}=K_{p} y \sqrt{p_{c}}
\end{aligned}
$$

where

$$
\left.\begin{array}{l}
K_{b}=\frac{\pi}{4} C_{b} d_{b}^{2} \sqrt{2 / \rho}, K_{c}=\frac{\pi}{4} C_{d} d_{c}^{2} \sqrt{2 / \rho}, \\
K_{s}=\frac{\pi d_{s} \delta_{s}^{3}}{12 \mu l_{s}}, K_{p}=\pi C_{d} d_{v} \sin \theta_{p} \sqrt{2 / \rho},
\end{array}\right\}
$$

and $K_{i}(i=1,2,3)$ are calculated using the algorithm explained in [9], adding a few modification.

\section{Method for Simulation and Estimation}

MATLAB/Simulink was used for modeling of Eqs. (1)(16). Runge-Kutta method of fourth-order was used as the solver. Although the time step for calculation was fixed step of $0.01 \mathrm{~ms}$, the time step of data was $0.1 \mathrm{~ms}$. On a real situation of the relief valve usage, input flow rate to the valve varies from zero to the rated flow, namely, the valve closes initially. For the calculation of such situation, shorter time step and longer calculation time are required to prevent a memory-overflow. This 
study is, however, mainly aiming at screening of change of response with various parameters, that the calculation was made with the main valve opened initially.

Before starting the calculation of the response, pressures and valve displacement at the initial relief flow rate were computed and read in as initial values. These values were approximation, so that vibration occurred just after starting calculation. However, the vibration disappeared after $0.2 \mathrm{~s}$ with all of the conditions. Step-change of the input flow rate to the valve was made when $0.25 \mathrm{~s}$. The calculation of the response was made until $1.25 \mathrm{~s}$. The pressures and the valve displacement were almost settled down after $1.25 \mathrm{~s}$ in most cases.

Since preset pressure varies slightly with each of the initial conditions, calculation results cannot compared with each other in their absolute values. Therefore, all pressure data were made dimensionless by the initial supply pressure.

Estimation method for the calculation results was as follows. Settling time was determined as the time until the main valve displacement was settled in the settled value $\pm 5 \%$ of step width, where the step width is the difference between the initial- and settled values of the main valve displacement. As shown in Fig. 4, pressure increment $P_{o}$, pressure overshoot $P_{1}$, peak rising time $T_{1}$, damping ratio $r_{d}$ and period of damped vibration $T_{d}$ were found from waveform of supply pressure.

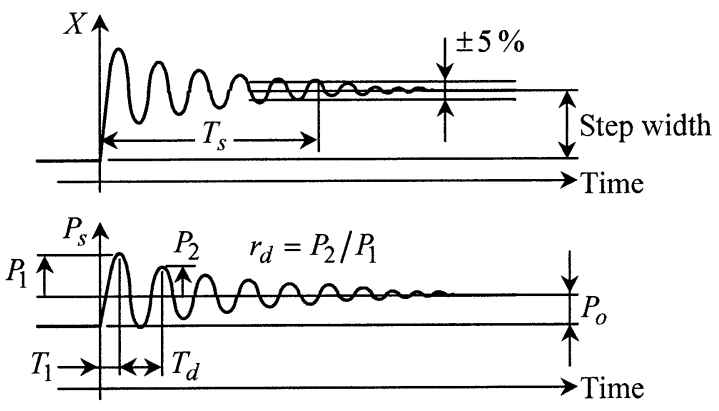

Figure 4 Measures of step response

\section{Conditions for Calculation}

Physical properties of fluid and reference parameters are listed in Table 1. The discharge coefficients $C_{d}$ and $C_{b}$ were assumed to be constant. The calculation was made varying the following parameters: mass of valves $m_{m}$ and $m_{p}$, volume of chambers $V_{p}$ and $V_{c}$, diameter of the damping orifice $d_{c}$, and spring constant for the pilot valve $k_{p}$. Variations of each of parameters were $-20,-10$, $0,+10$ and $+20[\%]$ of the corresponding reference value. The conditions for calculation were the followings:

* Preset pressure: $7 \mathrm{MPa}$

* Initial relief flow rate: $5 \mathrm{~L} / \mathrm{min}$

* Step width of flow rate into the valve: $15 \mathrm{~L} / \mathrm{min}$
Table 1 Physical properties and reference parameters

\begin{tabular}{|c|c|}
\hline $\begin{array}{l}\mu=0.5482[\mathrm{mPa} \cdot \mathrm{s}] \\
C_{d}=0.67[-]\end{array}$ & $\begin{array}{l}\rho=988\left[\mathrm{~kg} / \mathrm{m}^{3}\right] \quad \beta=2.2[\mathrm{GPa}] \\
C_{b}=0.67[-]\end{array}$ \\
\hline$m_{m}=65[\mathrm{~g}]$ & $m_{p}=8[\mathrm{~g}]$ \\
\hline$d_{c}=1.0[\mathrm{~mm}]$ & $k_{p}=158[\mathrm{~N} / \mathrm{mm}]$ \\
\hline$V_{p}=1.46 \times 10^{-6}\left[\mathrm{~m}^{3}\right]$ & $V_{c}=0.953 \times 10^{-6}\left[\mathrm{~m}^{3}\right]$ \\
\hline$V_{m}=2.34 \times 10^{-6}\left[\mathrm{~m}^{3}\right]$ & $V_{s}=0.01\left[\mathrm{~m}^{3}\right]$ \\
\hline$c_{m}=0[\mathrm{~N} \cdot \mathrm{s} / \mathrm{m}]$ & $c_{p}=0[\mathrm{~N} \cdot \mathrm{s} / \mathrm{m}]$ \\
\hline
\end{tabular}

\section{SIMULATION RESULTS AND DISCUSSION}

Figure 5 shows dimensionless waveforms of the supply pressure and the valve displacement with conditions of Table 1. The estimated values are as follows:

* Pressure increment $P_{o}$ :

$0.144 \%$

* Pressure overshoot $P_{1}$ :

$3.18 \%$

* Peak rising time $T_{1}$ :

$6.7 \mathrm{~ms}$

* Damping ratio $r_{d}$ : 0.851

* Period of damped vibration $T_{d}: 25.1 \mathrm{~ms}$

* Settling time $T_{s}$ :

$540 \mathrm{~ms}$

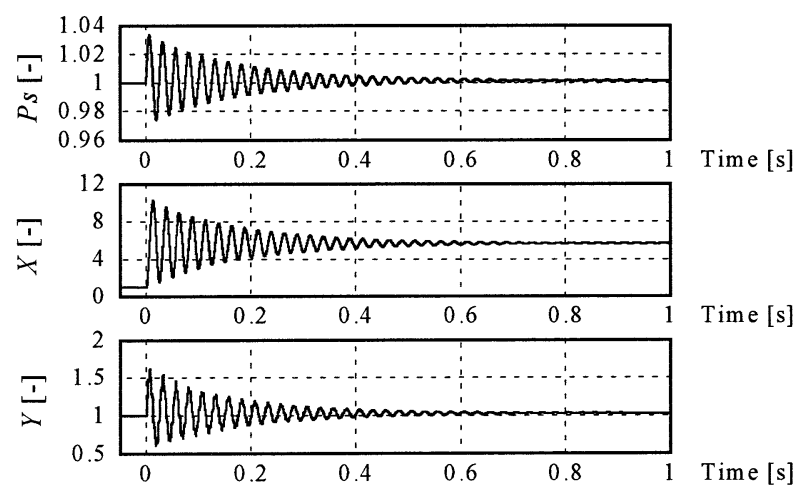

Figure 5 Step response

In the following, the variation of estimated values to the variation of each parameter will be shown. The pressure increment $P_{o}$ is, however, shown lastly since it has been affected only by $d_{c}$ and $k_{p}$.

\section{Influence of $\boldsymbol{m}_{\boldsymbol{m}}$ and $\boldsymbol{m}_{\boldsymbol{p}}$}

Figure 6 shows the influence of mass of the main valve. $T_{1}$ and $T_{d}$ did not change. However, all the other estimated values indicate that lighter main valve is preferable.

Figure 7 shows the influence of mass of the pilot valve. Any significant trend are not observed in this result. The waveforms of the pilot valve displacement (Fig. 8) show that lighter pilot valve is preferable on the damping for high frequency vibration. 


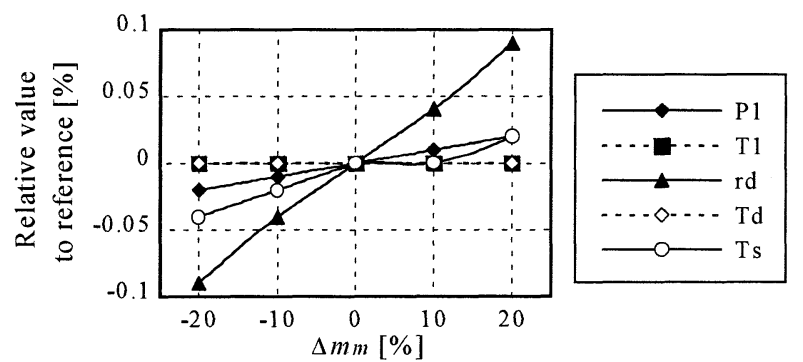

Figure 6 Influence of $m_{m}$

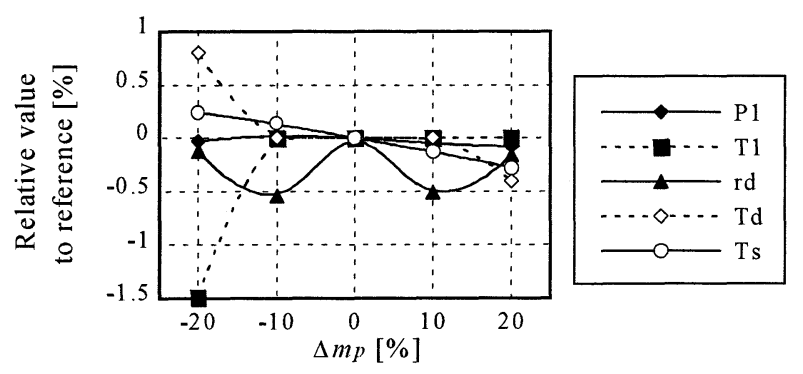

Figure 7 Influence of $m_{p}$
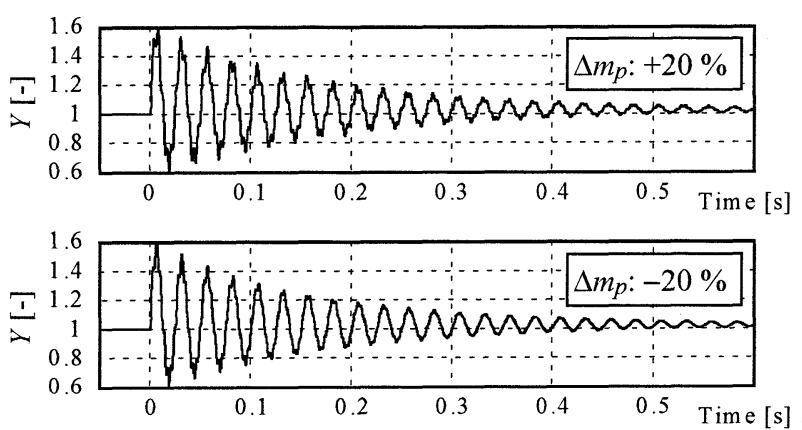

Figure 8 Waveforms of pilot valve displacement

\section{Influence of $V_{p}$ and $V_{c}$}

Figure 9 and 10 shows the influence of $V_{p}$ and $V_{c}$, respectively. Both graphs show clear tendency that large $V_{p}$ and small $V_{c}$ contributes the stability of the valve. Particularly, small $V_{c}$ has much effect on decrease of the settling time.

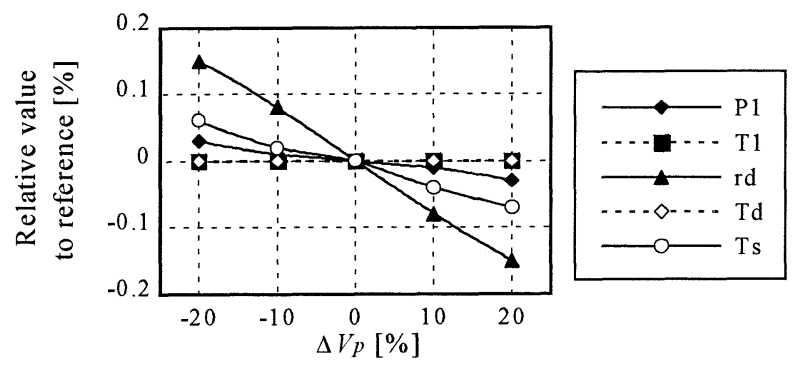

Figure 9 Influence of $V_{p}$

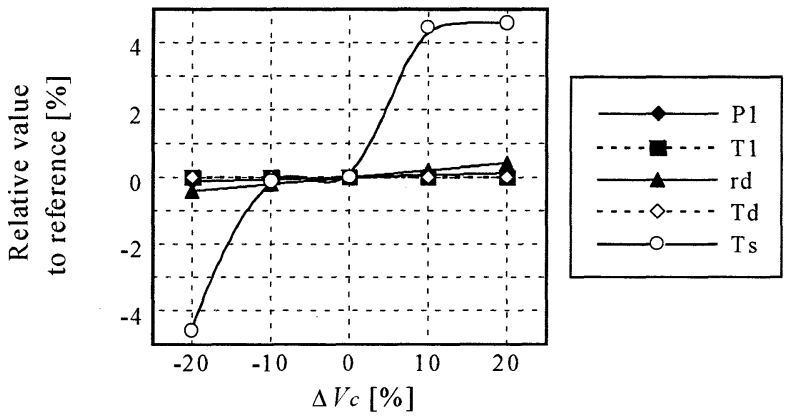

Figure 10 Influence of $V_{c}$

\section{Influence of $\boldsymbol{d}_{c}$}

Figure 11 shows the influence of the damping orifice diameter, which indicates that the diameter has large influence on the stability. These phenomena resulted from the fact that the pressure difference between the orifice is inversely proportional to the orifice diameter to the power of four.

Small $d_{c}$ made damped pressure vibration, whereas the overshoot, peak rising time and period of damped vibration became quite large. In contrast, if $d_{c}$ was large, the overshoot, peak rising time and damping ratio became small, whereas the pilot valve vibrated with high frequency. In both cases, the settling time became longer. To summarize, there exists an optimal value for the damping orifice diameter. In addition, its small vibration has large influence on the stability of the valve. This implies that machining error has large influence on stability. To cope with the sensitivity of the orifice, a capillary would be preferable as the damping restrictor.

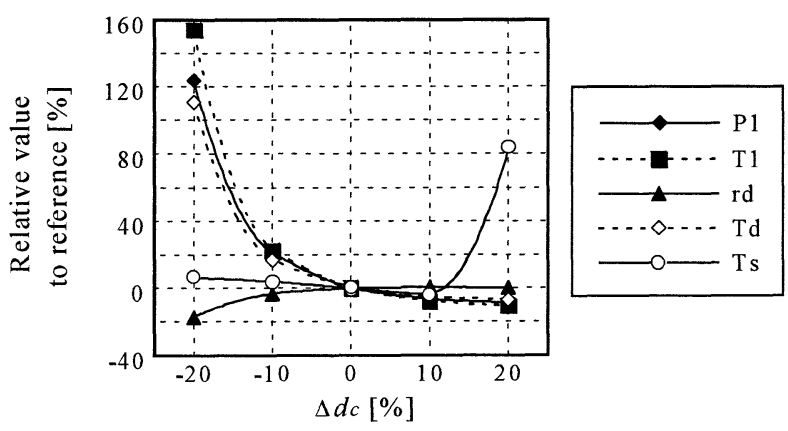

Figure 11 Influence of $d_{c}$

\section{Influence of $\boldsymbol{k}_{\boldsymbol{p}}$}

Figure 12 shows the influence of spring constant for the pilot valve. When a weak spring was used, the corresponding overshoot, peak rising time and period of damped vibration decreased, whereas the damping ratio increased. Behavior of the settling time does not show monotonic change with $k_{p}$, which suggest that a more precise analysis is necessary. 


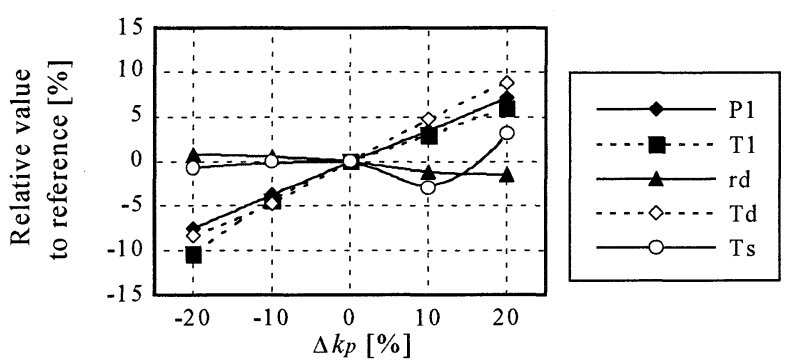

Figure 12 Influence of $k_{p}$

\section{Influence of $\boldsymbol{d}_{\boldsymbol{c}}$ and $\boldsymbol{k}_{\boldsymbol{p}}$ on Pressure Increment}

Figure 13 shows the influence of $d_{c}$ and $k_{p}$ on pressure increment. The pressure increment increases with increase of $k_{p}$ and with decrease of $d_{c}$. Particularly, small $d_{c}$ makes the pressure increment remarkably large, which implies that the pressure override becomes large.

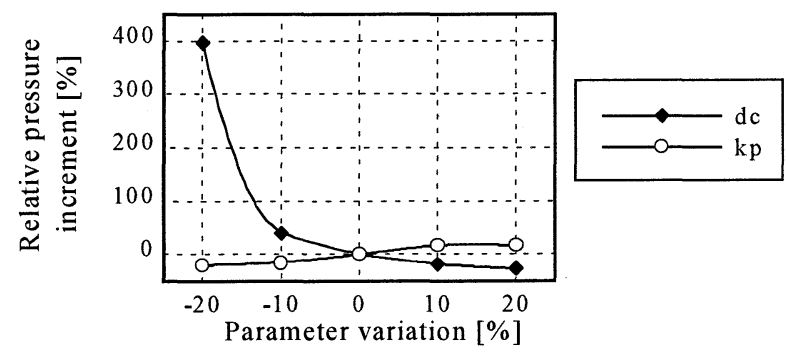

Figure 13 Affects of $d_{c}$ and $k_{p}$ on pressure increment

\section{Overall Improvement}

Based on the above investigation, the calculation was made again with variation of all six parameters as listed in Table 2. Although the damping ratio increases slightly, all the other estimated values decreased. The results are summarized in Table 3.

Table 2 Variation of six parameters

\begin{tabular}{lll}
\hline$\Delta m_{m}:-20 \%$ & $\Delta m_{p}:-20 \%$ & $\Delta V_{p}:+20 \%$ \\
$\Delta V_{c}:-20 \%$ & $\Delta d_{c}:+10 \%$ & $\Delta k_{p}:-20 \%$ \\
\hline
\end{tabular}

Table 3 Results with conditions of Tables 1 and 2

\begin{tabular}{llll}
\hline & Table 1 & Table 2 & Rel. value [\%] \\
\hline$P_{o}[\%]$ & 0.144 & 0.106 & -26.4 \\
$P[\%]$ & 3.18 & 2.75 & -13.4 \\
$T_{1}[\mathrm{~ms}]$ & 6.7 & 5.7 & -14.9 \\
$r_{d}[-]$ & 0.851 & 0.855 & +0.47 \\
$T_{d}[\mathrm{~ms}]$ & 25.1 & 22.2 & -11.6 \\
$T_{s}[\mathrm{~ms}]$ & 540 & 499 & -7.65 \\
\hline
\end{tabular}

\section{CONCLUSION}

Analysis of dynamic characteristics was made for a direct-pressure sensing water hydraulic relief valve, in which four hydrostatic bearings support the main valve to reduce hysteresis in the static characteristics of the valve. Investigation on the step response of the valve by simulation is presented for the various values of the design parameters. Stability of the valve was discussed with respect of pressure overshoot, peak rising time, damping ratio, period of damping vibration and settling time.

The factor affecting the stability most is the diameter of the damping orifice that is inserted between the mainand pilot valves to give damping force to the main valve. In addition, the spring constant for the pilot valve and the volume of a chamber between the damping orifice and the poppet valve have much influence.

\section{REFERENCES}

1 Park, S-H, Kitagawa, A., Kawashima, M., Lee, J-K and Wu, P., A Development of Water Hydraulic High Speed Solenoid Valve, The Fifth JFPS Int. Sympo. on Fluid Power, 1, 2002, pp.137-142.

2 Yao, D., Burton, R., Nikiforuk, P., Ukrainetz, P. and Zhou, Q., Research and Development of a Direct Pressure Sensing Relief Valve, Proc. The Fourth Int. Conf. on Fluid Power Transmission and Control, 1997, pp.150-155.

3 Berger, J., Kavitationserosion und Maßnahmen zu ihrer Vermeidung in Hydraulikanlagen für HFAFlüssigkeiten, Dissertation der TH Aachen, 1983.

4 Suzuki, K., and Urata, E., Improvement of Cavitation Resistive Property of a Water Hydraulic Relief Valve, Proc. The Eighth SICFP, 1, 2003, pp.265-276.

5 Shin, Y. C., Static and Dynamic Characteristics of a Two Stage Pilot Relief Valve, Trans. ASME J. Dyn. Syst. Meas. Control, 1991, 113-2, pp.280-288.

6 Yao, D., Bitner, D., Burton, R. and Nikiforuk, P., Some Static and Dynamic Considerations in the Design of a Direct Sensing Pressure Relief Valve, Fluid Power Engineering: Challenges and Solutions, Tenth Bath Int. Fluid Power Workshop (Edited by K. A. Edge and C. R. Burrows), 1998, pp.214-229.

7 Nakanishi, T., Hayashi, S., Hayase, T., Shirai, A., Jotatsu, M. and Kawamoto, H., Numerical Simulation of Water Hydraulic Relief Valve, The Fourth JHPS Int. Sympo. on Fluid Power, 1999, pp.555-560.

8 Hayashi, S., Nakanishi, T., Hayase, T. and Shirai, A., Analysis of Dynamic Characteristics of Water Hydraulic Relief Valve, Trans. JFPS (in Japanese), 2002, 33-7, pp.149-155.

9 Suzuki, K. and Urata, E., Analysis of Hydrostatic Bearing for Water Hydraulic Servovalve, The Sixth SICFP, 1, 1999, pp.179-190. 